Revista Brasileira de Agricultura Irrigada v.8, nº 6, p.528 - 537, 2014

ISSN 1982-7679 (On-line)

Fortaleza, CE, INOVAGRI - http://www.inovagri.org.br

DOI: $10.7127 /$ rbai.v8n600264

Protocolo 264.14 - 23/09/2014 Aprovado em 08/11/2014

\title{
GOTEJADORES SUBMETIDOS A APLICAÇÃO DE FERRO SOLÚVEL
}

\author{
Lilian Cristina Castro de Carvalho ${ }^{1,}$ Rubens Duarte Coelho ${ }^{2}$, Marconi Batista Teixeira ${ }^{3}$, \\ Fernando Nobre Cunha ${ }^{4}$, Nelmício Furtado da Silva ${ }^{5}$
}

\begin{abstract}
RESUMO
Esta pesquisa foi desenvolvida visando quantificar possíveis distúrbios de vazão em emissores gotejadores submetidos à aplicação de ferro solúvel, sólidos em suspensão (partículas de solo). Foi realizado o experimento com 26 modelos de tubos gotejadores em uso, com suas respectivas linhas gotejadoras montadas em uma bancada de ensaios em estrutura metálica localizada no Laboratório de Irrigação, da Escola Superior de Agricultura "Luiz de Queiroz" ESALQ/USP. No experimento, foi realizado um tratamento onde se avaliou a susceptibilidade de diferentes tubos gotejadores em uso ao entupimento por ferro solúvel. Os modelos 19 e 21 apresentaram o pior desempenho quando submetidos aos ensaios realizados com o tratamento (hidróxido de ferro + água LAB).
\end{abstract}

Palavras-chave: emissores, entupimento, qualidade da água, hidróxido de ferro.

\section{DRIPPERS SUBMITTED THE APPLICATION OF SOLUBLE IRON}

\begin{abstract}
This research project was developed to quantify possible disturbances of flow rate in drip emitters subject to the application of soluble iron. The experiment were carried during 12 months period, using 26 models of used drip tubes. The tests were conducted on a bench test located at the Irrigation and Drainage Laboratory of the University of Sao Paulo (ESALQ / USP). Experiment carried out one treatment which evaluated the susceptibility of different used drip tube for clogging by soluble iron. Models 19 and 21 showed the worst performance when subjected to the tests treatment (iron hydroxide + water LAB).
\end{abstract}

Keywords: emitter, clogging, water quality, iron hydroxide

\footnotetext{
${ }^{1}$ Professora do Instituto Federal do Ceará, IFCE. Av. Dr. Guarani, 317, Derby Clube, 62042-030, Sobral, CE. email: liliancarv@ifce.edu.br.

${ }^{2}$ Eng. Agrônomo, Prof. Livre Docente, DER - Departamento de Engenharia Rural, Escola Superior de Agricultura Luiz de Queiroz, Universidade de São Paulo, Piracicaba, SP, C.P.: 9, CEP: 13418-900, fone (0xx19) 3447-8551, email: rdcoelho@esalq.usp.br

3 Eng. Agrônomo, Prof. Dr. Instituto Federal Goiano - IFGoiano - Rio Verde, GO, email: marconibt@gmail.com

${ }^{4}$ Eng. Agrônomo, Doutorando em Ciências Agrárias - Agronomia, IFGoiano - Câmpus Rio Verde, Rio Verde, GO, email: fernandonobrecunha@ hotmail.com

${ }^{5}$ Eng. Agrônomo, Doutorando em Ciências Agrárias - Agronomia, IFGoiano - Câmpus Rio Verde, Rio Verde, GO, email: nelmiciofurtado@gmail.com
} 


\section{INTRODUÇÃO}

O ferro nas águas é proveniente da intemperização do material geológico de origem, como solos e rochas, bem como do carreamento de materiais sólidos do entorno da bacia, proveniente das ações antrópicas. $\mathrm{Na}$ água de irrigação o ferro encontra-se em sua forma, reduzido $\left(\mathrm{Fe}^{+2}\right)$, mais solúvel, que ao passar pelo sistema de filtragem oxida-se, precipitando e adquirindo a forma de $\mathrm{Fe}^{+3}$ (MANTOVANI, 2006).

$\mathrm{O}$ entupimento de emissores é um grave problema associado ao gotejamento, pois dificulta a operação de sistemas de irrigação, é de difícil detecção e sua limpeza e substituição podem ser bastante onerosas (NAKAYAMA; BUCKS, 1991).

A obstrução de emissores, causada por bactérias que oxidam o ferro apresentam um difícil controle. Até mesmo concentrações férreas muito pequenas, menores que $0,5 \mathrm{mg}$ $\mathrm{L}^{-1}$, são suficientes para promover o crescimento bacteriano, que geralmente apresenta coloração avermelhada. A precipitação do ferro e o rápido crescimento das bactérias criam um material volumoso que pode entupir um sistema de irrigação por gotejamento completamente em questão de algumas semanas (TEIXEIRA, 2006).

O entupimento pode ser parcial, reduzindo a uniformidade de aplicação, ou total, interrompendo por completo o funcionamento do sistema, causando sérios problemas às culturas, devido à deficiência hídrica (CARARO, 2004).

Conforme Capra e Scicolone (2004) a filtração da água é a principal ação preventiva quanto ao entupimento de emissores, causada por partículas tanto de origem mineral quanto orgânica. Se a água de irrigação for residuária e apresentar elevada concentração de sólidos suspensos, recomenda-se o emprego de sedimentadores, eficientes na remoção de areia e silte.

Em um sistema de gotejamento deve se prezar sempre por uma boa uniformidade de distribuição de água. A manutenção de elevada uniformidade de aplicação e distribuição de água nos sistemas de irrigação por gotejamento torna-se fundamental para uma eficiente irrigação e, consequentemente, um melhor aproveitamento dos recursos hídricos e redução dos custos (RIBEIRO et al., 2012). Para Cunha et al. (2014) a chance de encontrar o entupimento parcial ou total em um tubo gotejador diminui conforme diminui a quantidade de pontos (emissores) avaliados, pois a dispersão das partículas sólidas no diâmetro interno tem maior influência na uniformidade conforme diminui o número de pontos avaliados e aumenta a obstrução total, sendo a uniformidade bastante variável quando sob obstrução parcial.

O objetivo deste experimento foi avaliar a susceptibilidade de diferentes tubos gotejadores ao entupimento por ferro solúvel na água de irrigação (óxido de ferro, sulfato ferroso e hidróxido de ferro).

\section{MATERIAL E MÉTODOS}

A presente pesquisa foi conduzida no Laboratório de Irrigação de Irrigação da Escola Superior de Agricultura "Luiz de Queiroz" ESALQ/USP, localizada no município de Piracicaba - SP, cujo clima é classificado como Cwa - subtropical úmido, segundo classificação climática de Köppen, temperatura média máxima superior a $22^{\circ} \mathrm{C}$ e média mínima de 
$18^{\circ} \mathrm{C}$, ocorrendo chuvas de verão e secas de inverno.

O experimento foi desenvolvido em uma bancada de ensaios, construída em estrutura metálica composta por três andares, com $11 \mathrm{~m}$ de comprimento, $4 \mathrm{~m}$ de largura e $5,8 \mathrm{~m}$ de altura, sendo cada andar da bancada independente dos demais.

Os andares foram divididos em duas partes, sendo cada uma composta por diferentes níveis para a inserção das linhas gotejadoras que foram unidas no início e no final da bancada por registros e conexões de PVC. Para a condução da água e montagem das linhas de gotejadores do ensaio utilizou-se um registro de 2 " na linha principal e um registro de $3 / 4$ " na entrada de cada nível. Na entrada de cada módulo da bancada, foi instalada uma tomada de pressão, permitindo o ajuste da pressão a cada medição de vazão, e se necessário, ajustada àquela preestabelecida. Para a medição e monitoramento da pressão de serviço, foi utilizado um manômetro com faixa de leitura de $0-700 \mathrm{kPa}$, calibrado previamente por um manômetro de peso morto.

O sistema de pressurização utilizado no experimento foi composto por um conjunto de motobomba centrífuga da marca KSB, modelo KSB Hydrobloc C 750, cuja operação de funcionamento foi realizada manualmente, obedecendo rigorosamente os horários de início e fim de cada aplicação. Para evitar a entrada de partículas em suspensão no sistema, foi utilizado um filtro de disco de $120 \mathrm{mesh} / \mathrm{Amiad}$, com capacidade para $15 \mathrm{~m}^{3} \mathrm{~h}^{-1}$ de vazão, cuja limpeza foi feita a cada 12 horas de funcionamento.

No preparo e armazenamento das soluções utilizaram-se caixas de amianto, com capacidade para $1000 \mathrm{~L}$, que foram conectadas ao conjunto motobomba por meio de uma sucção de 0,06 m de diâmetro, através de um adaptador de caixa d'água e o bombeamento de cada solução foi controlado por um registro de esfera de 0,06 m, instalado na extremidade da sucção dentro da caixa, permitindo o bombeamento da solução.

O sistema de aplicação da solução foi adaptado de tal forma que permitia um processo de recirculação da mesma, onde a solução gotejada era recolhida por dois conjuntos de telhas de aço zincado (forradas com filme plástico), com uma inclinação de $3 \%$, aonde conduzia a solução para uma calha de zinco revestida com fibra de vidro, localizada no centro do módulo, que retornava a solução para a caixa da respectiva captação, através de um conjunto de tubos PVC de $100 \mathrm{~mm}$.

Ao final da aplicação, os registros eram fechados com o sistema ainda em funcionamento, para evitar o retorno da solução ao reservatório, garantindo assim que a solução permanecesse em contato com toda a superfície interna da linha gotejadora. Para evitar uma perda acentuada da solução ao longo da semana, foram colocadas cortinas de plásticos nas laterais da bancada de ensaio. Após cada ensaio de vazão, o sistema permanecia desligado por um dia, com o objetivo de se fazer limpeza, preparo da nova solução, reparos e manutenção do sistema.

O experimento foi realizado no módulo 3 da bancada de ensaio, no setor 5 , onde realizouse o tratamento, com duração de 648 horas. $\mathrm{O}$ setor 5 era composto por 26 modelos diferentes de tubos gotejadores, onde destes 9 eram convencionais $(1,2,3,4,5,6,7,8$ e 9) e 17 autocompensantes $(10,11,12,13,14,15,16$, $17,18,19,20,21,22,23,24,25$ e 26$)$.

No tratamento foi aplicado $20,0 \mathrm{mg} \mathrm{L}^{-1}$ de ferro solúvel $\left(\mathrm{Fe}^{+2}\right)$, tendo o hidróxido de ferro 
como fonte do mesmo, associado a água LAB (água do laboratório) (Tabela 1). O tratamento realizado no experimento pode ser resumido da seguinte forma: tratamento (linhas gotejadoras do setor 5): 20,0 $\mathrm{mg} \mathrm{L}^{-1}$ de $\mathrm{Fe}^{+2}$ (hidróxido de ferro) + água LAB.

Tabela 1. Análise da água do Laboratório de Irrigação da ESALQ/USP, que foi utilizada na preparação da solução aplicada no tratamento.

\begin{tabular}{|c|c|c|}
\hline Parâmetro & Unidade & Resultado \\
\hline Alcalinidade $\left(2 \mathrm{CO}_{3}{ }^{2-}+\mathrm{HC}_{3}{ }^{-}\right)$ & $\mathrm{mg} \mathrm{L}^{1}$ & 35,8 \\
\hline Cloreto $\left(\mathrm{Cl}^{-}\right)$ & $\mathrm{mg} \mathrm{L}^{1}$ & 33,9 \\
\hline Nitrato $\left(\mathrm{N}-\mathrm{NO}_{3}\right)$ & $\mathrm{mg} \mathrm{L}^{1}$ & 20,5 \\
\hline Sulfato $\left(\mathrm{SO}_{4}{ }^{2-}\right)$ & $\mathrm{mg} \mathrm{L}^{1}$ & 149,3 \\
\hline Fósforo (P) & $\mathrm{mg} \mathrm{L}^{1}$ & 0,05 \\
\hline Nitrogênio Amoniacal $\left(\mathrm{N}-\mathrm{NH}_{3}\right)$ & $\mathrm{mg} \mathrm{L}^{1}$ & 0,11 \\
\hline Sódio $\left(\mathrm{Na}^{+}\right)$ & $\mathrm{mg} \mathrm{L}^{1}$ & 44,0 \\
\hline Potássio $\left(\mathrm{K}^{+}\right)$ & $\mathrm{mg} \mathrm{L}^{1}$ & 7,1 \\
\hline Cálcio $\left(\mathrm{Ca}^{2+}\right)$ & $\mathrm{mg} \mathrm{L}^{1}$ & 33,2 \\
\hline Magnésio $\left(\mathrm{Mg}^{2+}\right)$ & $\mathrm{mg} \mathrm{L}^{1}$ & 9,2 \\
\hline Ferro $\left(\mathrm{Fe}^{2+}\right)$ & $\mathrm{mg} \mathrm{L}^{1}$ & 0 \\
\hline Cobre $(\mathrm{Cu})$ & $\mathrm{mg} \mathrm{L}^{1}$ & 0,01 \\
\hline Manganês (Mn) & $\mathrm{mg} \mathrm{L}^{1}$ & 0,09 \\
\hline Zinco (Zn) & $\mathrm{mg} \mathrm{L}^{1}$ & 1,14 \\
\hline Boro (B) & $\mathrm{mg} \mathrm{L}^{1}$ & 0 \\
\hline Alumínio (Al) & $\mathrm{mg} \mathrm{L}^{1}$ & 0 \\
\hline Cor aparente & $\mathrm{PtCo}$ & 4 \\
\hline Turbidez & FTU & 4 \\
\hline Sedimentos em suspensão & $\mathrm{mg} \mathrm{L}^{1}$ & 6,0 \\
\hline Condutividade elétrica (CE) & $\mathrm{mS} \mathrm{cm} \mathrm{cm}^{-1}$ & 0,37 \\
\hline $\mathrm{pH}$ & ---- & 7,5 \\
\hline Gás carbônico $\left(\mathrm{CO}_{2}\right)$ & $\mathrm{mg} \mathrm{L}^{1}$ & 1,9 \\
\hline Acidez $\left(\mathrm{CaCO}_{3}\right)$ & $\mathrm{mg} \mathrm{L}^{1}$ & 6,5 \\
\hline Dureza total $\left(\mathrm{CaCO}_{3}\right)^{*}$ & $\mathrm{mg} \mathrm{L}^{1}$ & 120,6 \\
\hline
\end{tabular}

*Dureza total calculada com base no equivalente de carbonato de cálcio $\left(\mathrm{CaCO}_{3}\right)$

Durante o ensaio foram mantidos os espaçamentos originais das linhas gotejadoras, com o objetivo de evitar diferenças relacionadas à influência de emendas e da proximidade dos emissores, reduzindo os erros e mantendo, assim, as mesmas condições das linhas utilizadas pelos irrigantes. Desta forma o número de gotejadores presentes na linha dependeu do espaçamento fornecido pelo fabricante, porém foi assegurado um número mínimo de 10 emissores para cada modelo analisado.

A Tabela 2 apresenta os emissores com suas características técnicas e a vazão mais comercializada pelos irrigantes. Em função dos emissores ensaiados serem produtos comerciais e os ensaios a que foram submetidos não serem normatizados, os dados e análises realizados em todos os ensaios foram codificados para evitar qualquer tipo de especulação comercial dos resultados apresentados. A codificação utilizada na representação dos modelos de emissores, não tem nenhuma relação com os nomes comerciais dos produtos e nem tampouco com a sequência de emissores apresentados na Tabela 2.

Tabela 2. Características técnicas: fluxo, vazão, diâmetro nominal $(\varnothing \mathrm{N})$ e espaçamento entre gotejadores dos modelos utilizados no experimento.

\begin{tabular}{|c|c|c|c|c|c|}
\hline Fabricante & Modelo & Fluxo & $\begin{array}{l}\text { Vazão } \\
\left(\mathrm{L} \mathrm{h}^{-1}\right)\end{array}$ & $\begin{array}{c}\varnothing \mathrm{N} \\
(\mathrm{mm})\end{array}$ & $\begin{array}{c}\text { Espaçamento } \\
\text { entre gotejadores } \\
(\mathrm{m})\end{array}$ \\
\hline \multirow{4}{*}{ Naandan } & Naan tif PC & $\mathrm{AC}$ & 1,6 & 16 & 0,50 \\
\hline & Naan Paz & $\mathrm{NC}$ & 2,0 & 16 & 0,75 \\
\hline & Naan PC & $\mathrm{AC}$ & 2,1 & 16 & 0,80 \\
\hline & Naan PC & $\mathrm{AC}$ & 3,8 & 16 & 0,90 \\
\hline \multirow{6}{*}{ Netafin } & Drip Net & $\mathrm{AC}$ & 1,6 & 16 & 0,75 \\
\hline & Uniran & $\mathrm{AC}$ & 1,6 & 16 & 0,33 \\
\hline & Ram & $\mathrm{AC}$ & 2,3 & 16 & 0,50 \\
\hline & Ram & $\mathrm{AC}$ & 2,3 & 17 & 0,50 \\
\hline & Tiran & $\mathrm{NC}$ & 2,05 & 16 & 0,75 \\
\hline & $\begin{array}{c}\text { Super } \\
\text { Typhoon }\end{array}$ & $\mathrm{NC}$ & 2,0 & 16 & 0,60 \\
\hline \multirow{6}{*}{ Plastro } & Hydrogol & $\mathrm{NC}$ & 3,0 & 17 & 0,40 \\
\hline & Hydro Pc & $\mathrm{AC}$ & 2,0 & 17 & 0,80 \\
\hline & Hydro Pc & $\mathrm{AC}$ & 2,2 & 17 & 0,80 \\
\hline & Hydro Pc & $\mathrm{AC}$ & 2,2 & $16 / 25$ & 0,75 \\
\hline & Hydro Pc Nd & $\mathrm{AC}$ & 2,35 & $16 / 40$ & 0,80 \\
\hline & Hydro Drip & $\mathrm{AC}$ & 2,0 & 16 & 0,80 \\
\hline \multirow[t]{2}{*}{ Amanco } & Carbo Drip & $\mathrm{AC}$ & 2,0 & 17 & 0,80 \\
\hline & $\begin{array}{c}\text { Carbo Drip } \\
\text { Cd/Ac }\end{array}$ & $\mathrm{NC}$ & 2,2 & 16 & 0,50 \\
\hline \multirow{4}{*}{ Irrimon } & Twin Plus & $\mathrm{AC}$ & 1,8 & 17,5 & 1,00 \\
\hline & Vip Line & $\mathrm{AC}$ & 3,6 & 16 & 1,00 \\
\hline & Irridrip Plus & $\mathrm{AC}$ & 2,5 & 16 & 1,00 \\
\hline & Irriloc & $\mathrm{NC}$ & 1,1 & 16,4 & 0,40 \\
\hline Azud & Azudline & $\mathrm{NC}$ & 1,4 & 17 & 0,50 \\
\hline Toro Ag & Drip In & $\mathrm{AC}$ & 2,5 & 17 & 0,75 \\
\hline Petroísa & Petroísa G1 & $\mathrm{NC}$ & 1,5 & 16 & 0,30 \\
\hline Queen Gil & Queen Gil & $\mathrm{NC}$ & 4,0 & 16,5 & 0,10 \\
\hline
\end{tabular}

Fonte: Catálogo dos fabricantes 
Depois de tabulados os pesos, procederam-se os cálculos da vazão, vazão relativa e do coeficiente de variação de vazão, através das Equações de 1 a 3.

$$
q=\frac{P}{1000 t d} 60
$$

em que:

$\mathrm{q}$ - vazão do gotejador, $\mathrm{L} \mathrm{h}^{-1}$;

$\mathrm{P}$ - peso da água coletada, $\mathrm{g}$;

$\mathrm{t}$ - tempo de coleta, min e

$d$ - densidade da água utilizada no ensaio, $\mathrm{g} \mathrm{L}^{-}$

${ }^{1}$ (o valor médio utilizado para conversão da água para $25^{\circ} \mathrm{C}$, foi de 0,997 ).

$$
Q_{r}=\frac{Q_{x, y}}{Q_{i}}
$$

em que:

$\mathrm{Q}_{\mathrm{r}}$ - vazão relativa, \%;

$\mathrm{Q}_{\mathrm{x}, \mathrm{y}}$ - vazão de um emissor $\mathrm{x}$ num dia y de irrigação, $\mathrm{L} \mathrm{h}^{-1} \mathrm{e}$

$\mathrm{Q}_{\mathrm{i}}$ - vazão desse emissor no primeiro dia de irrigação, $\mathrm{L} \mathrm{h}^{-1}$.

$$
C V_{q}=\frac{s_{\text {usado }}}{\bar{q}_{\text {usado }}} 100
$$

em que:

$\mathrm{CV}_{q}$ - coeficiente de variação da vazão, \%;

$\mathrm{s}_{\text {usado }}$ - desvio padrão da vazão dos gotejadores usados, $\mathrm{L} \mathrm{h}^{-1}$; e

$\bar{q}_{\text {usado }}$ - vazão média do gotejador usado, $\mathrm{Lh}^{-1}$.

Para avaliação dos coeficientes de variação utilizou-se a classificação dos valores propostas pela Associação Brasileira de Normas Técnicas - ABNT (1986), logo quaisquer comparação entre os modelos e o tempo de irrigação foi baseada na classificação proposta pela ABNT (1986), conforme Tabela 3.

Tabela 3. Classificação de emissores quanto à uniformidade de vazão, segundo ABNT (12:02.08-022/86)

\begin{tabular}{cc}
\hline Classificação & CVF \\
\hline Boa & $<10 \%$ \\
média & 10 a $20 \%$ \\
marginal & 20 a $30 \%$ \\
inaceitável & $>30 \%$
\end{tabular}

Fonte: Associação Brasileira de Normas Técnicas ABNT (1986)

\section{RESULTADOS E DISCUSSÃO}

Nas Figuras 1, 2, 3 e 4 encontram-se os valores de vazão relativa (\%) para os emissores avaliados com tratamento de $20,0 \mathrm{mg} \mathrm{L}^{-1}$ de $\mathrm{Fe}^{+2}$ (hidróxido de ferro) + água LAB. É importante lembrar que os emissores ensaiados no tratamento são usados, de modo que, a vazão inicial utilizada para obtenção da vazão relativa não foi a dos gotejadores novos e sim a vazão obtida na primeira leitura após o tratamento de desobstrução dos emissores.

Conforme as Figuras de 1 a 4 os emissores avaliados apresentaram comportamento diferenciado quanto à redução de vazão, em função do entupimento. Na Figura 1 observa-se que os gotejadores dos modelos 1 e 24 foram os que apresentaram uma maior variação de vazão, onde o modelo 1 apresentou uma redução de vazão de $35 \%$ após $216 \mathrm{~h}$ de funcionamento, no entanto a partir deste momento apresentou elevação de vazão, chegando a um aumento de $44 \%$ ao final do experimento (648h); o modelo 24 apresentou $100 \%$ de elevação de vazão após $288 \mathrm{~h}$ de aplicação, reduzindo em seguida e ao 
final de $648 \mathrm{~h}$ de funcionamento apresentou uma elevação de vazão de 39 \%. Esta elevação de vazão deve-se, possivelmente, a uma fase inicial do entupimento com aumento de vazão, devido a possíveis danos na membrana de compensação dos emissores autocompensantes. Os demais modelos (2, 3, 7 e 13) mantiveram-se praticamente constantes por todo o ensaio. Coelho et al. (2014) observaram a variação da taxa de fluxo em 20 modelos de gotejadores submetidos a aplicação de ferro, argila do solo e da água com alta concentração orgânica (algas), e concluíram que os modelos de gotejadores ensaiados apresentaram maior redução de vazão quando se aplicou água contendo elevado teor de ferro total associado à carga orgânica (algas) mais solo argiloso.

Observando a Figura 2, os modelos 4, 6, 9 e 10 apresentaram redução de vazão, após $648 \mathrm{~h}$ de funcionamento, da ordem de 10, 11, 17 e $15 \%$, respectivamente e os modelos 17 e 25 , apresentaram aumento de 4 e $6 \%$, respectivamente, ao final do ensaio.

Analisando os modelos 5, 11, 14, 15, 16, e 22 (Figura 3) e estabelecendo comparação entre o tempo de funcionamento de 0 e 648 horas verificou-se redução de vazão igual a 29, 27, 28, 29, 40 e 33\%, respectivamente.

As reduções de vazão mais acentuadas ocorreram nos modelos 19 e 21 (Figura 4) que apresentaram obstrução total da vazão a partir de 360 e 648 horas de funcionamento, respectivamente.

O modelo 12, também não apresentou um bom resultado, pois sofreu uma redução de vazão de $71 \%$. Nos modelos 18, 23 e 26 as reduções de vazão foram de 51,31 e $62 \%$ ao final do experimento (648 h). Estes resultados estão corroboram Batista et al. (2013), que trabalharam com água residuária de suinocultura e observaram que as características de sólidos suspensos, ferro total e população bacteriana representaram risco severo de entupimento de gotejadores e que as porcentagens de entupimento dos gotejadores podem ser menores em função do menor tempo de funcionamento do equipamento para aplicação sustentável da água residuária da suinocultura.

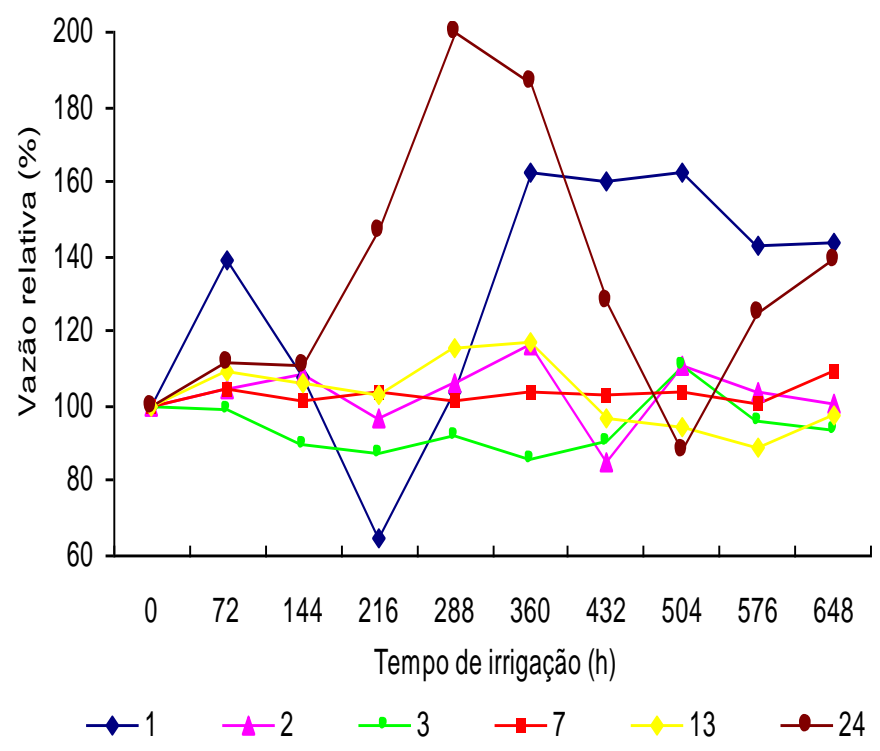

Figura 1. Vazão relativa (\%) dos gotejadores 1, 2, 3, 7, 13 e 24 em função do tempo de irrigação.

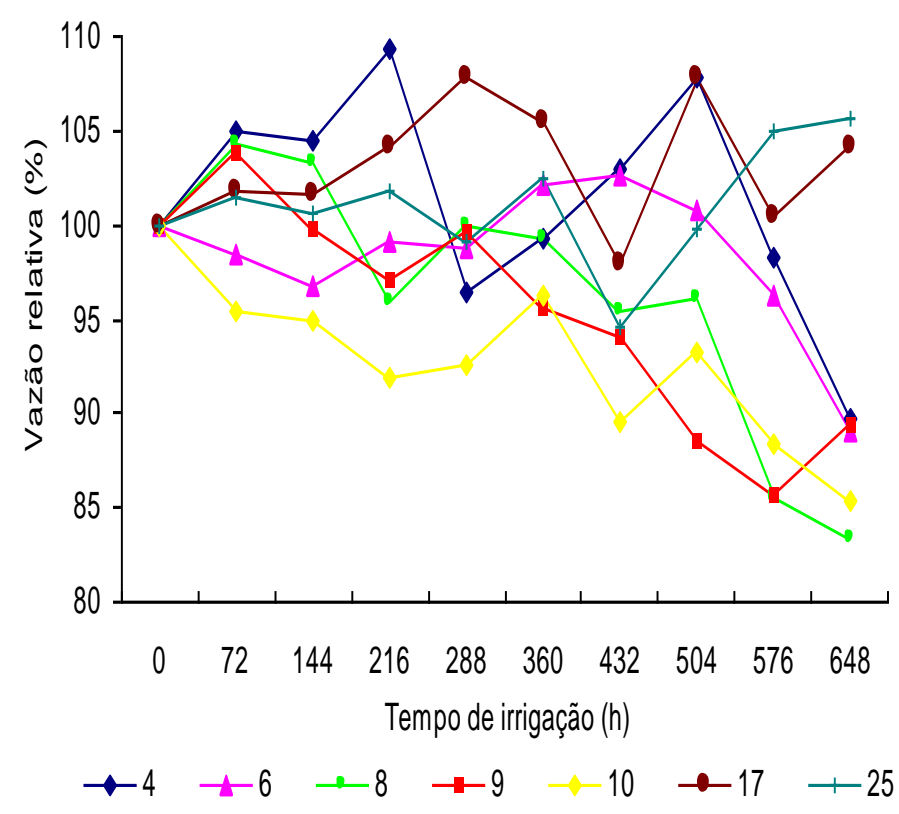

Figura 2. Vazão relativa (\%) dos gotejadores 4, 6, 8, $9,10,17$ e 25 em função do tempo de irrigação. 


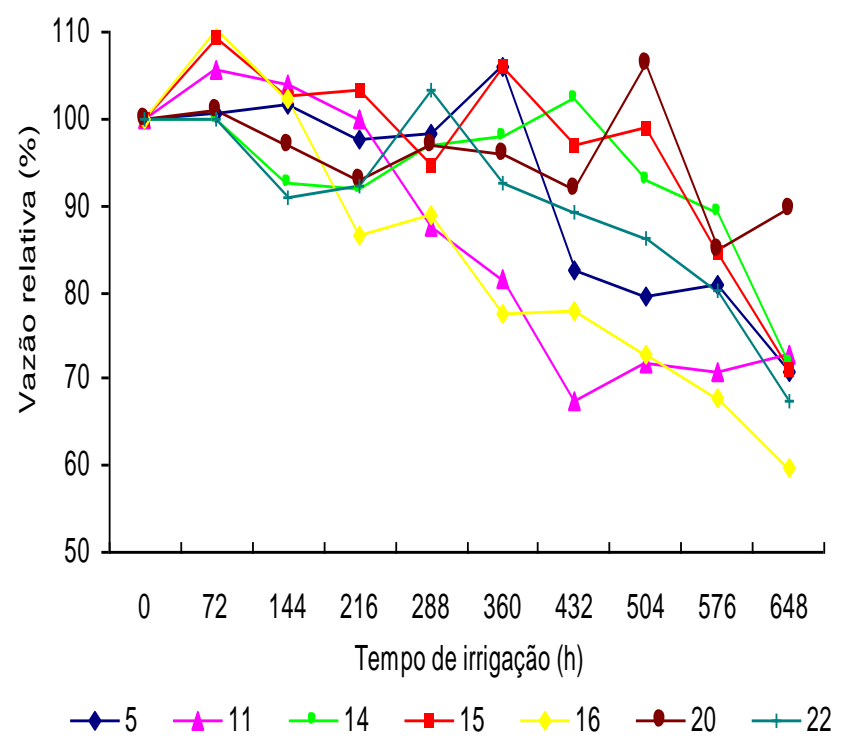

Figura 3. Vazão relativa (\%) dos gotejadores 5, 11, $14,15,16,20$ e 22 em função do tempo de irrigação.

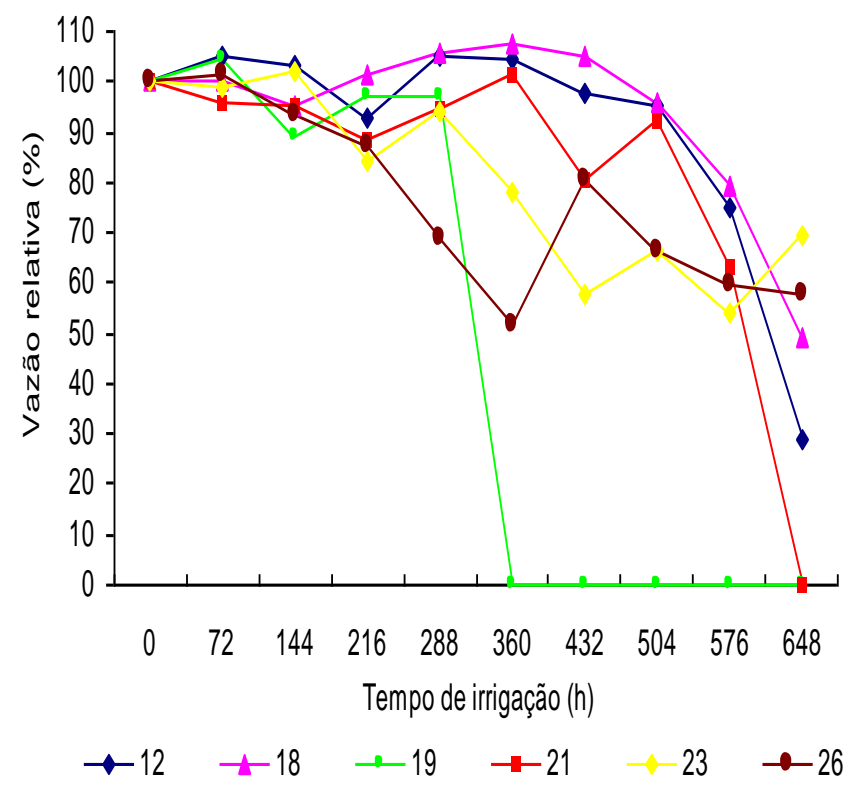

Figura 4. Vazão relativa (\%) dos gotejadores 12, 18, $19,21,23$ e 26 em função do tempo de irrigação.

Nas Figuras 5, 6, 7 e 8 encontram-se os valores de coeficiente de variação de vazão (\%) para os emissores avaliados com o tratamento de 20,0 $\mathrm{mg} \mathrm{L}^{-1}$ de $\mathrm{Fe}^{+2}$ (hidróxido de ferro) + água LAB. De acordo com estas Figuras podese observar que o coeficiente de variação de vazão inicial (zero hora), dos emissores usados, variou de 3,3 (modelo 9) a 93,9\% (modelo 23).
Os emissores dos modelos de 4 a 10, os de 12 a 15 e os dos modelos 18, 20, 22, 25 e 26, mantiveram seus valores de coeficiente de variação inicial dentro dos considerados bons de acordo com a classificação da ABNT (1986), indicando que estes modelos, mesmo tendo sido utilizados anteriormente, possuem boa qualidade. Ainda para o coeficiente de variação de vazão inicial os modelos 1 e 17 são considerados médios, os modelos 2, 24 e 16 marginais e os modelos 3, 11, 19, 21 e 23 inaceitáveis.

O maior valor de coeficiente de variação de vazão foi apresentado pelo modelo 23 , que chegou a $159,3 \%$ a partir de 576 horas de funcionamento, porém reduziu este valor para $39,1 \%$ ao final do ensaio (648 h).

Na Figura 5, observa-se que o modelo 13 manteve seu coeficiente de variação de vazão dentro dos valores considerados bons, durante todo o ensaio, o modelo 17, embora após 648 horas de funcionamento tenha apresentado um aumento no valor do coeficiente de variação, também se manteve numa faixa considerada média. O modelo 2 variou seus valores de coeficiente de variação de vazão entre a faixa do bom ao marginal até o final do ensaio. $\mathrm{O}$ modelo 3, mesmo tendo apresentado coeficiente de variação inicial inaceitável (35,3\%) e mantido este valor praticamente constante até o final do ensaio, quando comparado aos valores de vazão relativa, notou-se que não houve variação da mesma ao longo de todo o experimento. Os modelos 1 e 24 apresentaram de coeficiente de variação de vazão de 66,2 e $53,1 \%$, após 648 horas de funcionamento.

Observando a Figura 6 constatou-se que o modelo 10 manteve seu valor de coeficiente de 
variação dentro da faixa considerada aceitável, durante todo o ensaio. Os modelos 4,6 e 8 mantiveram-se praticamente constante ao longo do experimento, porém após 648 horas de funcionamento apresentaram valores inaceitáveis de coeficiente de variação de vazão, a saber: 32,8; 30 e 39,9\%, respectivamente. Já os modelos 9, 17 e 25 apresentaram algumas alterações em seus valores de coeficiente de variação, no decorrer do experimento, contudo ao final do ensaio, demonstraram valores de coeficiente de variação de vazão de 10,8; 15,7 e 19,1; respectivamente, portanto dentro da faixa considerada média segundo a ABNT (1986).

Conforme se observa na Figura 7, apenas o modelo 20 manteve seu coeficiente de variação dentro da faixa considerada aceitável, por todo o ensaio, os modelos 5, 11, 14, 15, 16 e 22 apresentaram valores de coeficiente de variação superiores a $30 \%$, sendo considerados, portanto inaceitáveis.

O pior desempenho foi observado pelos modelos 19 e 21 (Figura 8) que mostraram elevada suscetibilidade ao entupimento chegando a uma obstrução total de seus emissores a partir de 360 e 648 horas de funcionamento, respectivamente. Os modelos 12, 18 e 26 passaram a apresentar valores inadequados de coeficiente de variação de vazão a partir de 648, 576 e 144 horas de funcionamento, respectivamente. Com base nestes resultados é possível recomendar conforme Busato et al. (2012) que água com alto teor de ferro só deve ser utilizada em irrigação por gotejamento associada a um sistema de tratamento para evitar problemas de entupimento dos emissores.

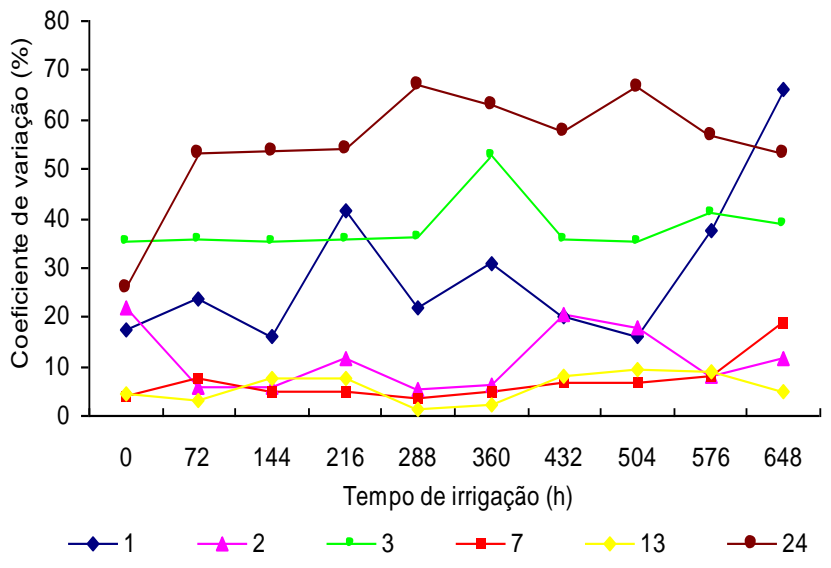

Figura 5. Coeficiente de variação (\%) dos gotejadores 1, 2, 3, 7, 13 e 24 em função do tempo de irrigação.

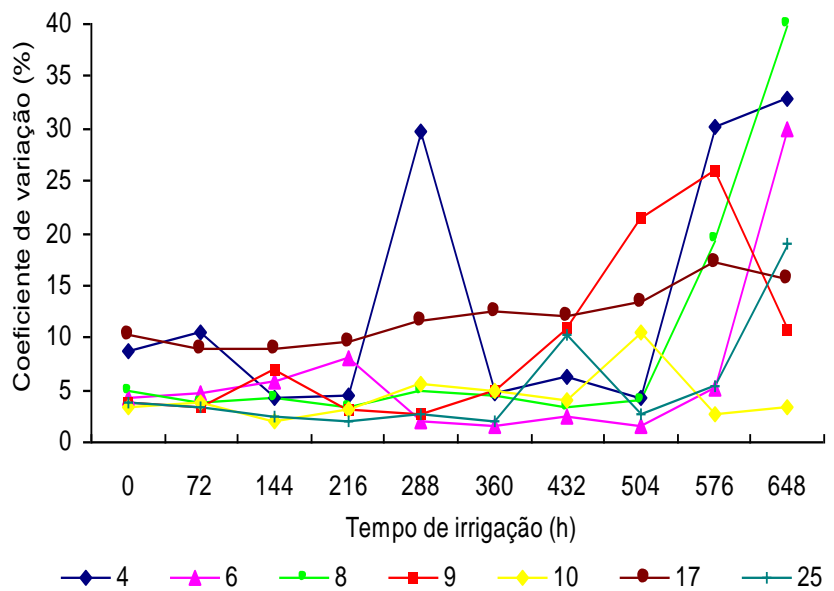

Figura 6. Coeficiente de variação (\%) dos gotejadores $4,6,8,9,10,17$ e 25 em função do tempo de irrigação.

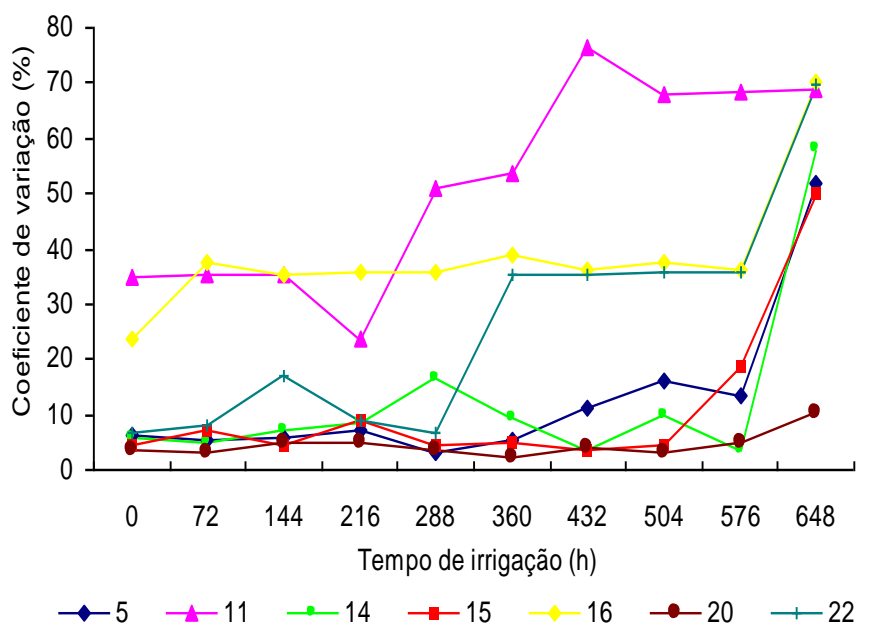

Figura 7. Coeficiente de variação (\%) dos gotejadores $5,11,14,15,16,20$ e 22 em função do tempo de irrigação. 


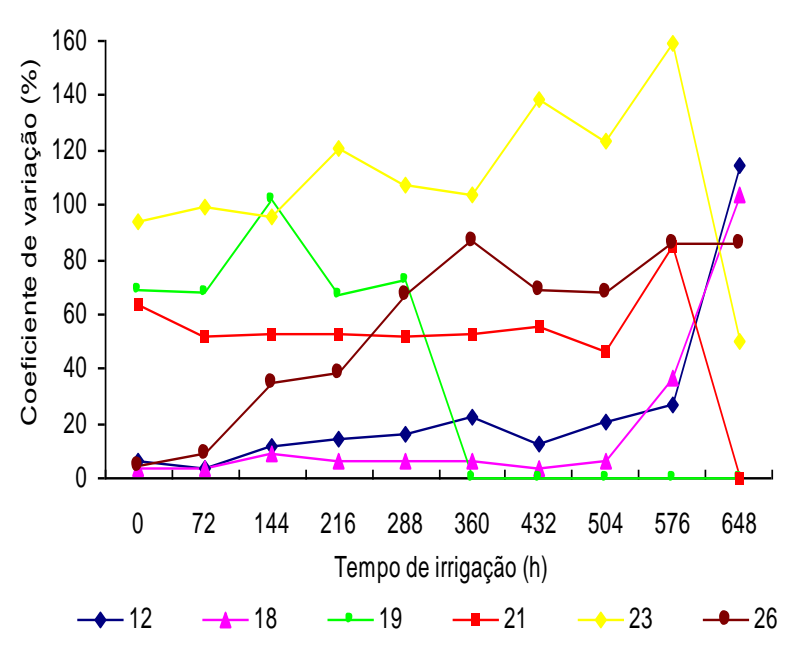

Figura 8. Coeficiente de variação (\%) dos gotejadores 12, 18, 19, 21, 23 e 26 em função do tempo de irrigação.

\section{CONCLUSÕES}

Os modelos de tubos gotejadores apresentaram desempenhos variáveis, tanto na suscetibilidade ao entupimento quanto no coeficiente de variação de vazão.

A velocidade com que o entupimento parcial tende ao entupimento total propende a ser maior em função da arquitetura interna dos emissores.

Os modelos 19 e 21 apresentaram os piores desempenhos quando submetidos a tratamento com hidróxido de ferro + água LAB.

\section{REFERÊNCIAS BIBLIOGRÁFICAS}

\section{ASSOCIAÇÃO BRASILEIRA DE NORMAS TÉCNICAS. Emissores para sistemas de irrigação localizada: avaliação das características operacionais; PNBR 12: 02-08- 021. São Paulo, 1986. 7p.}

BATISTA, R. O.; OLIVEIRA, R. A.; SANTOS, D. B.; OLIVEIRA, A. F. M.; AZEVEDO, C. A. V.; MEDEIROS, S. S. Obstrução e uniformidade de aplicação em sistemas de irrigação por gotejamento aplicando-se efluente da suinocultura. Revista brasileira engenharia agrícola ambiental, Campina Grande, v.17, n.7 Jul. 2013.

BUSATO, C. C. M.; SOARES, A. A.; REIS, E. F., RAMOS, M. M. Influência do entupimento no desempenho de gotejadores aplicando água ferruginosa. Engenharia Ambiental, Espírito Santo do Pinhal, v. 9, n. 2, p. 119-128, abr/ jun. 2012.

CAPRA, A.; SCICOLONE, B. Emitter and filter tests for wastewater reuse by drip irrigation. Agricultural Water Management, Amsterdam, v. 68, n. 2, p. 135- 149, 2004.

CARARO, D.C. Manejo de irrigação por gotejamento para aplicação de água residuária visando a minimização do entupimento de emissores. 2004. 130p. Tese (Doutorado) - Escola Superior de Agricultura Luiz de Queiroz, Piracicaba, 2004.

COELHO, R. D.; TEIXEIRA, M. B.; CARVALHO, L. C. C.; CUNHA, F. C.; SILVA, N. F. Distúrbios de vazão em gotejadores devido o uso de água com presença de ferro. Revista Brasileira de Agricultura Irrigada, v.8, $\mathrm{n}^{\text {o. }}$ 3, p. 234 - 246, 2014

CUNHA, F. N.; SILVA, N. F.; TEIXEIRA, M. B.; RIBEIRO, P. H. P.; MOURA, L. M. F.; SANTOS, C. C. Repetibilidade de um sistema de irrigação por gotejamento sob entupimento. Revista Brasileira de Agricultura Irrigada, v.8, no. 4, p.343 - 353, 2014.

MANTOVANI, E.C.; BERNARDO, S.; PALARETTI, L.F. Irrigação: princípios e métodos. Viçosa: Ed UFV, 2006. 318 p. 
NAKAYAMA, F.S.; BUCKS, D.A. Water quality in drip/trickle irrigation: a review. Irrigation Science, New York, v. 12, p. 187192, 1991.

RIBEIRO, P. A. A.; TEIXEIRA, M. B.; COELHO, R. D.; FRANCO, E. M.; SILVA, N. F.; CARVAlHO, L. C. C.; ALVES, M. E. B. Gotejadores submetidos a condições críticas de qualidade da água. Brazilian Journal of
Irrigation and Drainage, Botucatu, Ed. Especial, p. 368 - 379, 2012.

TEIXEIRA, M.B. Efeitos de dosagens extremas de cloro e pH na vazão de gotejadores autocompensantes (irrigação localizada). 2006. 322 p. Tese (Doutorado em Irrigação e Drenagem) - Escola Superior de Agricultura "Luiz de Queiroz", Universidade de São Paulo. Piracicaba, 2006. 